\title{
Cancer screening inequities in a time of primary care reform: a population-based longitudinal study in Ontario, Canada
}

\author{
Aisha K. Lofters ${ }^{1,2,3,4,5^{*}}$ (D), Amy Mark ${ }^{5}$, Monica Taljaard ${ }^{5,6}$, Michael E. Green ${ }^{5,7}$, Richard H. Glazier 1,2,3,4,5 \\ and Simone Dahrouge $\mathrm{e}^{5,8,9}$
}

\begin{abstract}
Background: Primary care has been reformed in recent years in Ontario, Canada, with a move away from traditional fee-for-service to enhanced fee-for-service and capitation-based models. It is unclear how new models have affected disparities in cancer screening. We evaluated whether Ontario's enhanced fee-for-service model was associated with a change in the gaps in cancer screening for people living with low income and people who are foreign-born.

Methods: We conducted a population-based longitudinal analysis from 2002 to 2013 of Ontario family physicians who transitioned from traditional fee-for-service to enhanced fee-for-service. The binary outcomes of interest were adherence to cervical, breast and colorectal cancer screening recommendations. Outcomes were analyzed using mixed-effects logistic regression. Analyses produced annual odds ratios comparing the odds of being up-to-date for screening among patients in enhanced fee-for-service versus patients in traditional fee-for-service for each social stratum separately. We calculated the ratios of stratum-specific odds ratios to assess whether the transition from traditional to enhanced fee-for-service was associated with a change in screening gaps between immigrants and long-term residents, and between people in the lowest and highest neighbourhood income quintiles.

Results: Throughout the study period, cancer screening was consistently lower among immigrants and among people in the lowest income quintile. Transition to enhanced fee-for-service was generally associated with increased screening uptake for all, however for most years, ratios of ratios were significantly less than 1 for all three cancer screening types, indicating that there was a widening of the screening gap between immigrants and long-term residents and between people living in the lowest vs. highest income quintile associated with transitions.
\end{abstract}

Conclusion: The transition to enhanced fee-for-service in Ontario was generally associated with a widening of screening inequities for foreign-born and low-income patients.

Keywords: Cancer screening, Primary care, Health equity, Primary care reform, Health disparities

\section{Background}

Screening for cancers, specifically cervical, breast and colorectal cancer $(\mathrm{CRC})$, are integral components of primary care, with proven benefits for cancer morbidity and mortality. For example, for CRC screening, it has been estimated that if $70 \%$ of screen-eligible adults were

\footnotetext{
*Correspondence: Aisha.lofters@utoronto.ca

'Department of Family \& Community Medicine, St. Michael's Hospital, 30 Bond St, Toronto, ON M5B1W8, Canada

${ }^{2}$ Department of Family \& Community Medicine, University of Toronto, 500

University Ave. 5th Floor, Toronto, ON M5G1V7, Canada

Full list of author information is available at the end of the article
}

screened regularly with either a biennial fecal occult blood test or a colonoscopy every ten years, CRC mortality could decrease by as much as 15\% [1-5]. Mortality for cervical cancer has also dropped precipitously in Canada over recent decades to among the world's lowest due to regular screening [1-3]. However, despite a universal healthcare system and organized provincial screening programs [6-9], screening inequalities for cervical, breast, and colorectal cancer (CRC) are well documented in Ontario - Canada's most populous province. People living in low-income neighbourhoods and of low socioeconomic status have

(c) The Author(s). 2018 Open Access This article is distributed under the terms of the Creative Commons Attribution 4.0 International License (http://creativecommons.org/licenses/by/4.0/), which permits unrestricted use, distribution, and 
lower screening participation rates than their more advantaged peers for all three cancers [10-19]. Similarly, foreign-born persons are more likely to be under-screened for all three cancers, with certain immigrant groups being particularly vulnerable $[10,11,14,15,20-22]$. Barriers to screening are numerous, multi-level and complex, and exist at the patient, provider and healthcare system level [23-28].

Primary care reform in Ontario began in 2002, with the aims of expanding access to primary care, increasing emphasis on disease prevention, and improving quality of care [29-31]. Practices could transition from traditional fee-for-service to capitation-based payment models, wherein the majority of physician remuneration is based on the number and profile of patients under their care, or maintain their fee-for-service (FFS) payment structure but transition to an enhanced model of care, often referred to as enhanced fee-for-service (Table 1). Key elements of these new models were formalized patient enrolment (hence their name attribution "Patient Enrolment Model" or PEM) and financial incentives and bonuses, including for screening for cervical, breast and colorectal cancer for enrolled patients [29, 31, 32]. Adoption of the reform models was a success in that, by 2011, 77\% of Ontario residents were enrolled with a physician working in a PEM [29, 32, 33]. However, it is unclear whether and how the new PEMs models affected existing gaps in care across social strata.

We undertook this study to evaluate whether transition to the enhanced FFS model had an impact on the known gaps in cancer screening by immigration status and across socioeconomic strata. We hypothesized that transition to the enhanced FFS model would be associated with a reduction in screening inequities. We limited our evaluation to practices having transitioned from the traditional FFS model to the enhanced FFS model as the other PEMs also include significant payment reform in addition to the incentives and bonuses.

\section{Methods \\ Design}

We conducted a population-based longitudinal analysis from 2002 to 2013 of family physicians who transitioned from the traditional FFS to the enhanced FFS model during that time period in Ontario.

\section{Study setting and context}

Ontario is Canada's most populous province, with 13.8 million current residents, $28.5 \%$ of whom were born outside Canada [34]. Ontario's cervical and breast screening programs were established well before the study period: in 1997 and 1990 respectively [26], but ColonCancerCheck, Ontario's colorectal cancer screening program, was launched with a public awareness campaign in 2008 [35]. Cervical cancer screening guidelines changed in 2012, from a recommendation of annual Pap tests followed by screening every two to three years after three consecutive normal results, to a recommendation of screening every three years [36]. Current provincial cancer screening recommendations are at least one Pap test in the past three years for cervical cancer, at least one mammogram in the past two years for breast cancer, and at least one fecal occult blood test in the past two years for CRC screening. People are also considered up-to-date on CRC screening if they have had at least one colonoscopy in the past ten years or at least one sigmoidoscopy or barium enema in the past five years [6-9].

\section{Data sources}

The following datasets were linked using unique encoded identifiers and analyzed at the Institute for Clinical Evaluative Sciences (ICES). The Registered Persons Database (RPDB) includes the age, sex and postal code of all Ontario residents who are eligible for the universal Ontario Health Insurance Plan (OHIP). The OHIP

Table 1 Primary Care Models in Ontario

\begin{tabular}{|c|c|}
\hline $\begin{array}{l}\text { Primary Care Model } \\
\text { Types }\end{array}$ & Core Features \\
\hline $\begin{array}{l}\text { Traditional } \\
\text { fee-for-service }\end{array}$ & No enrolment of patients. Fee-for-service payment for services rendered \\
\hline $\begin{array}{l}\text { Enhanced } \\
\text { fee-for-service }^{a}\end{array}$ & $\begin{array}{l}\text { Enrolment of patients encouraged. Fee-for-service payment for services rendered. Incentives and bonuses (including. For } \\
\text { achieving cancer screening targets) for enrolled patients. Escalating cancer screening bonuses for achieving set targets } \\
\text { start if at least } 60 \% \text { of enrolled eligible women up-to-date on cervical screening, if at least } 55 \% \text { of enrolled eligible women } \\
\text { up-to-date on breast screening, or if at least } 15 \% \text { of enrolled eligible adults up-to-date on colorectal screening. }\end{array}$ \\
\hline Capitation-based & $\begin{array}{l}\text { Enrolment of patients required. Capitation payment covering a defined basket of services, with } 15 \% \text { of the usual fee-for-service } \\
\text { when these services are rendered and 100\% fee-for-service for services outside the basket. Incentives and bonuses (including } \\
\text { for achieving cancer screening targets as above) for enrolled patients }\end{array}$ \\
\hline $\begin{array}{l}\text { Capitation-based } \\
\text { team model }\end{array}$ & As above, including funding to create interdisciplinary teams \\
\hline $\begin{array}{l}\text { Community } \\
\text { health centres }\end{array}$ & Interdisciplinary teams, serve harder-to-reach populations, salaried payment \\
\hline
\end{tabular}


database contains procedural and diagnostic codes claimed by physicians in the province. The Immigration, Refugees and Citizenship Canada (IRCC) database consists of demographic information on Ontario's immigrants and refugees recorded on the date of issue of the landing visa, going back to 1985. The Ontario Cancer Registry documents all Ontario residents who have been newly diagnosed with, or died of, cancer. The Canadian Institute for Health Information Discharge Abstract Database contains clinical data from hospital discharges. The Ontario Breast Screening Program database contains data on screening mammograms. The Client Agency Program Enrolment (CAPE) database is updated bimonthly and identifies all Ontarians who are enrolled with a physician in a PEM, and the Corporate Provider Database records which family physicians participate in these PEMs. The Institute for Clinical Evaluative Sciences' Physicians' Database records demographic information about Ontario's physicians who are in active practice. This study was approved by the institutional review board at Sunnybrook Health Sciences Centre, Toronto, Canada.

\section{Study population - Physicians and patients}

We created an open cohort that included all family physicians who provided comprehensive primary care in Ontario and who transitioned from traditional FFS to enhanced FFS at some point between 2002 and 2011, and we followed physicians until 2013. Only physicians for whom we had at least two years pre and post transition data were retained in the analysis i.e. physicians who transitioned to another model type within two years were excluded.

We followed physicians longitudinally and established their corresponding patient rosters annually. Patients were attributed to individual physicians by using the CAPE database. Patients not formally enrolled with a primary care physician (including all patients prior to transition) were attributed by virtual enrolment i.e. they were attributed to the physician providing the most care financially to that patient in the two years prior to the end of each fiscal year based on a set of core primary care fee codes [16, 37-40]. In any given year, the patient dataset was further limited to individuals who were eligible for cervical, breast or CRC screening at the start of the two-year period preceding that year. We followed the provincial recommendations for screening and prevention to determine appropriateness of care [6-9]. To be eligible for cervical screening, women had to be 21 to 69 years of age and have no prior hysterectomy or prior diagnosis of invasive cervical cancer, endometrial cancer or ovarian cancer. We chose to apply the post-2012 cervical guidelines throughout the entire study period, as a three-year screening interval was also acceptable in the older guidelines. Women eligible for breast cancer screening were 50 to 69 years of age and had no prior diagnosis of invasive breast cancer. Patients considered eligible for CRC screening were 50 to 74 years of age and had no prior diagnoses of invasive CRC or inflammatory bowel disease.

\section{Outcomes}

The binary outcomes of interest were adherence to screening recommendations. Outcomes were measured annually at the patient level and reflected whether a patient was up-to-date on cervical, breast, or CRC screening. This was done separately for each type of screening that a patient was eligible for. At any point in time, the look-back window for outcome ascertainment was the two or three preceding years, depending on the recommendations. For example, a cervical screening manoeuvre conducted in any particular year would lead to a classification as up to date for that year and the next two years.

\section{Subgroup definitions}

The main subgroups of interest for the analysis were immigrant status and socio-economic strata. We identified immigrant patients as all those who were included in the IRCC database. Long-term residents of the province were defined as those not included in the IRCC database. These consisted of Canadian-born residents but also included immigrants who had landed prior to 1985 . To define socioeconomic strata, we used the Postal Code Conversion File and Statistics Canada 2006 Census data to determine the neighbourhood income quintiles based on patients' yearly postal code in the RPDB. For the purpose of the statistical analysis, we focused on the lowest versus highest income quintiles.

\section{Statistical analysis}

The unit of analysis was the individual patient, but inferences were made at the provider level. Outcomes were analyzed using mixed-effects logistic regression, estimated using the method of pseudo-likelihood based on linearization. The practice was modelled as a random effect to account for correlation among multiple patients belonging to the same practice. The main independent variable was a time-varying indicator, defined as the type of practice (traditional or enhanced FFS). As preliminary analyses demonstrated the presence of a strong secular trend (changes over time in screening rates prior to any transition) as well as differences in the observed effects of the transition by year, our model included fixed categorical terms for fiscal year and the interaction between fiscal year and the type of practice. Thus, our statistical models allowed comparisons between physicians who transitioned to enhanced FFS and physicians 
Table 2 Relative distributions of subgroups included in analyses in 2002 (first year of study period) and 2013 (last year of study period) by the screening type for which they were eligible

\begin{tabular}{|c|c|c|c|}
\hline \multirow{2}{*}{\multicolumn{2}{|c|}{ Number of physicians included in analysis }} & \multirow{3}{*}{$\begin{array}{l}2002 \\
4670 \\
2004009\end{array}$} & \multirow{3}{*}{$\begin{array}{l}2013 \\
2181 \\
1127283\end{array}$} \\
\hline & & & \\
\hline Cervical cancer screening & Number of patients eligible for screening & & \\
\hline & Number (\%) of screen-eligible patients classified as immigrants & $297501(14.9)$ & $356562(31.6)$ \\
\hline & \multicolumn{3}{|l|}{ Number (\%) of screen-eligible patients in income quintile } \\
\hline & Quintile 1 (lowest) & $358094(17.9)$ & $212638(18.9)$ \\
\hline & Q2 & $390558(19.5)$ & $229899(20.4)$ \\
\hline & Q3 & $411025(20.5)$ & $236375(21.0)$ \\
\hline & Q4 & $423745(21.1)$ & $240414(21.3)$ \\
\hline & Q5 (highest) & $420587(21.0)$ & $207957(18.5)$ \\
\hline \multirow[t]{8}{*}{ Breast cancer screening } & Number of patients eligible for screening & 560047 & 407625 \\
\hline & Number (\%) of screen-eligible patients classified as immigrants & $49583(8.9 \%)$ & $91766(22.5 \%)$ \\
\hline & Number (\%) of screen-eligible patients in income quintile & & \\
\hline & Q1 (lowest) & $94447(16.9 \%)$ & $71173(17.5 \%)$ \\
\hline & Q2 & 108869 (19.4\%) & 82187 (20.2\%) \\
\hline & Q3 & $114438(20.4 \%)$ & $84578(20.8 \%)$ \\
\hline & Q4 & $116199(20.8 \%)$ & $87072(21.4 \%)$ \\
\hline & Q5 (highest) & $126094(22.5 \%)$ & $82615(20.3 \%)$ \\
\hline \multirow[t]{8}{*}{ Colorectal cancer screening } & Number of patients eligible for screening & 1344891 & 925961 \\
\hline & Number (\%) of screen-eligible patients classified as immigrants & $108852(8.1 \%)$ & $206705(22.3 \%)$ \\
\hline & \multicolumn{3}{|l|}{ Number (\%) of screen-eligible patients in income quintile } \\
\hline & Q1 (lowest) & $221906(16.5 \%)$ & $160155(17.3 \%)$ \\
\hline & Q2 & $259256(19.3 \%)$ & $185972(20.1 \%)$ \\
\hline & Q3 & $275213(20.5 \%)$ & $192221(20.8 \%)$ \\
\hline & Q4 & $281479(20.9 \%)$ & $198951(21.5 \%)$ \\
\hline & Q5 (highest) & 307037 (22.8\%) & 188662 (20.4\%) \\
\hline
\end{tabular}

who remained behind in traditional FFS in each study year where transitions occurred.

To examine our primary questions of whether gaps in cancer screening across immigration status changed with the transition to enhanced FFS, we included two-way interaction terms between practice type and year, as well as three-way interaction terms between practice type, year and immigrant status. This analysis was then repeated for income quintile. The analyses produced annual odds ratios comparing the odds of being up to date for screening among patients in enhanced FFS versus patients in traditional FFS for each social stratum separately. We then calculated the ratios of these stratum-specific odds ratios, to directly assess whether the transition from traditional to enhanced FFS was associated with a narrowing or widening of the screening gaps between immigrants and long-term residents, and between people in the lowest and highest income quintiles. Traditional FFS practices, long-term residents, and people living in the highest income quintile were used as the reference groups for ratios of ratios. Accordingly, a ratio of odds ratios less than 1 indicated that the transition from traditional FFS to enhanced FFS was associated with a widening of screening gaps, while a ratio of odds ratios greater than 1 indicated that the transition was associated with a narrowing of screening gaps. We used the $95 \%$ confidence intervals to determine whether these ratios were statistically significant, whereby a confidence interval exclusive of 1 indicated a significant narrowing or widening of the screening gap.

To account for potential confounders (provider and patient characteristics associated with both the type of FFS model and screening outcomes), all our analyses adjusted for the following physician characteristics: sex, international medical graduate status, years since graduation, panel size and rurality, and patient characteristics: age, sex, co-morbidities and rurality. Rurality was determined based on the Rurality Index of Ontario score [41], and the level of co-morbidity was categorized using the Johns Hopkins Adjusted Clinical Groups Case-Mix System [42]. 


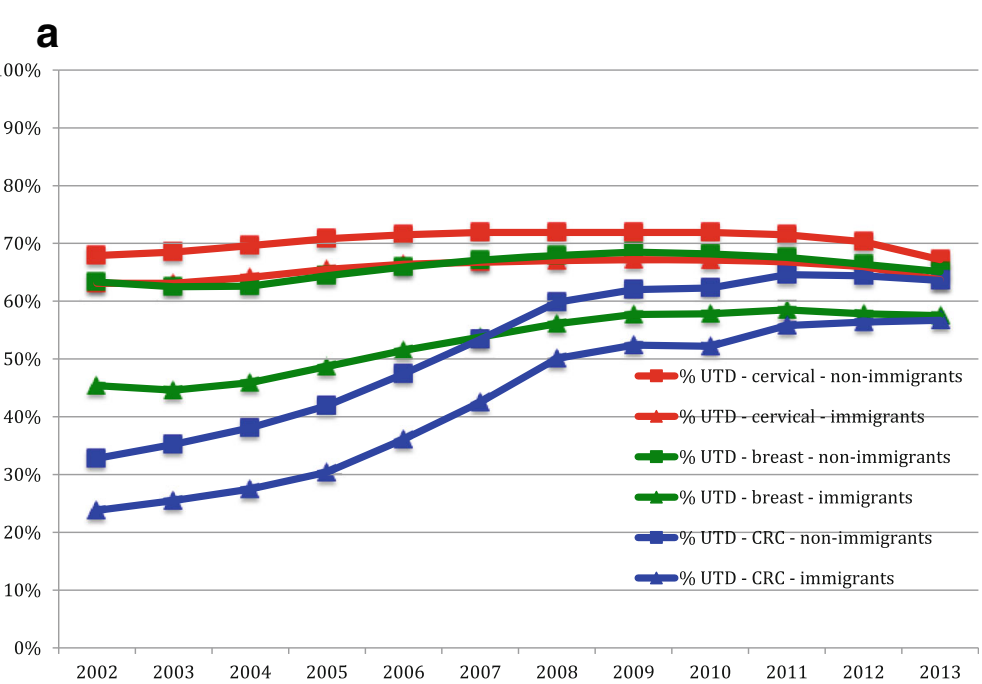

b

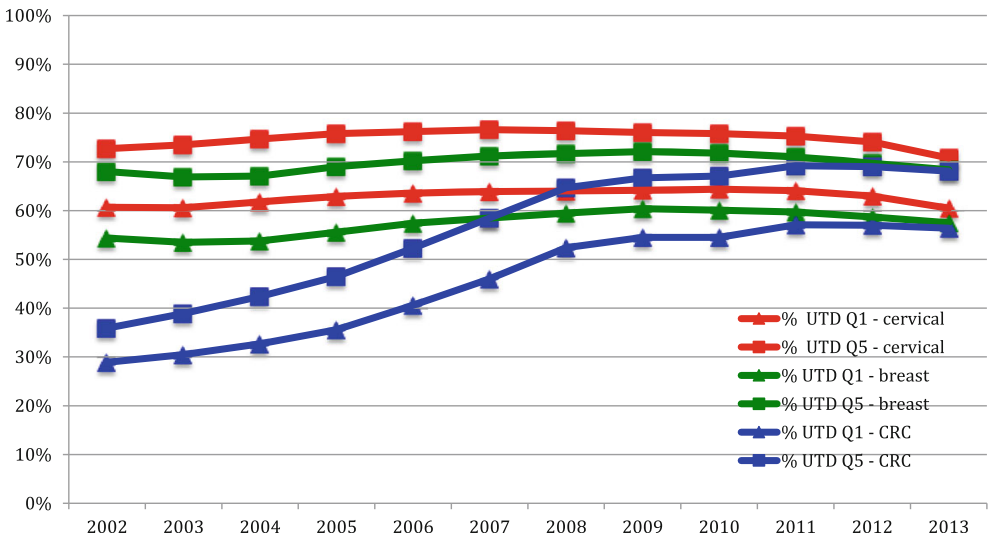

Fig. 1 Screening across time by fiscal year. UTD = proportion of patients up-to-date on that screening type for that fiscal year as defined by provincial guidelines. $C R C=$ colorectal cancer. $\mathbf{a}$ Stratified by immigrant status. $\mathbf{b}$ Stratified by income quintiles

All statistical tests were performed at the two-sided $5 \%$ level of significance, using SAS for Unix, version 9.1.3 (SAS Institute, Cary, NC).

\section{Results}

During the study period, 7336 family physicians transitioned from the traditional FFS primary care model to a PEM. Most of these (6145) adopted the enhanced FFS model initially, with 5268 (86\%) doing so from 2004 to 2007. In our cohort, we excluded physicians who transitioned back to traditional FFS [25], with less than two years of data post-transition (375), and who did not offer comprehensive primary care (412). There were 4670 physicians in our cohort in 2002 (Table 2). By 2013, there were 2811 physicians remaining in the cohort i.e. 2811 physicians who had not gone on to transition to another PEM type. The number of patients enrolled to these physicians and who were eligible for each type of cancer screening decreased from 2002 to 2013, in line with the decrease in the absolute number of physicians. However, the proportion of patients who were foreignborn increased.

By the end of the study period, screening rates for all included patients were $66.4 \%$ (cervical screening), $64.0 \%$ (breast screening) and 62.6\% (CRC screening). Throughout that period, screening was consistently lower among immigrants and among people in the lowest income quintile when compared to long-term residents and people in the highest income quintile respectively (Figs. 1a-b). CRC screening rates increased sharply from 2002. The gap in breast cancer screening between immigrants and longterm residents appeared to be reduced over time.

Figures 2a-c depict the observed rates of cervical, breast and CRC screening by fiscal year, stratified by the year of transition. Family physicians who were early adopters of the enhanced FFS model tended to have higher screening rates prior to transition, and the transition did not appear to introduce a change in either the 


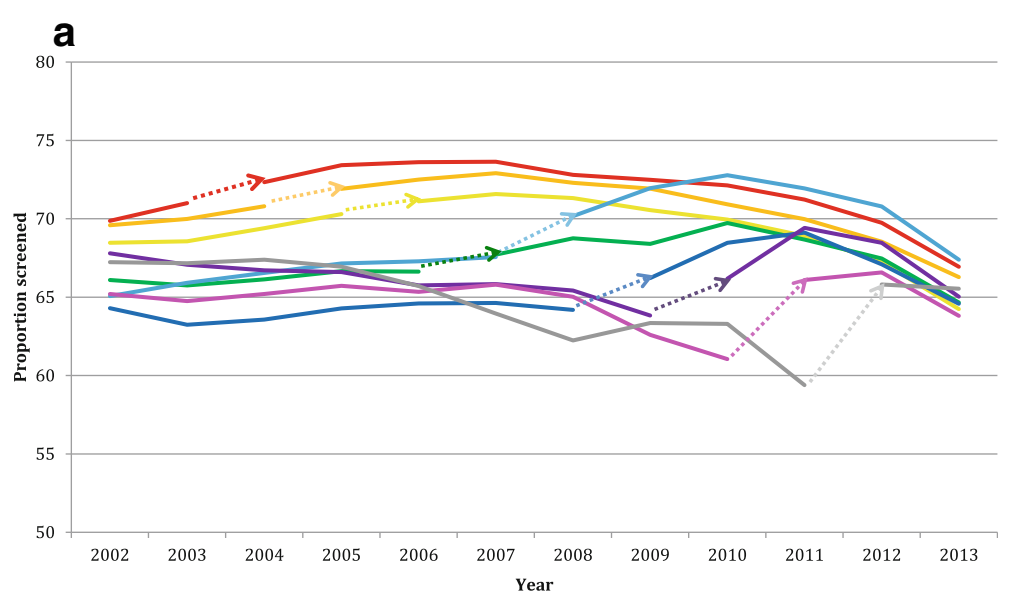

b

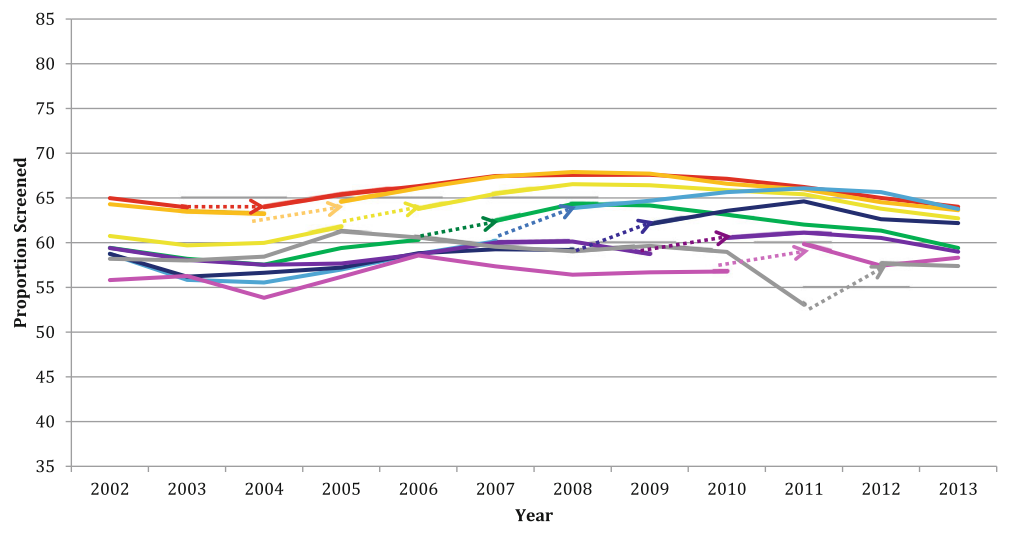

C

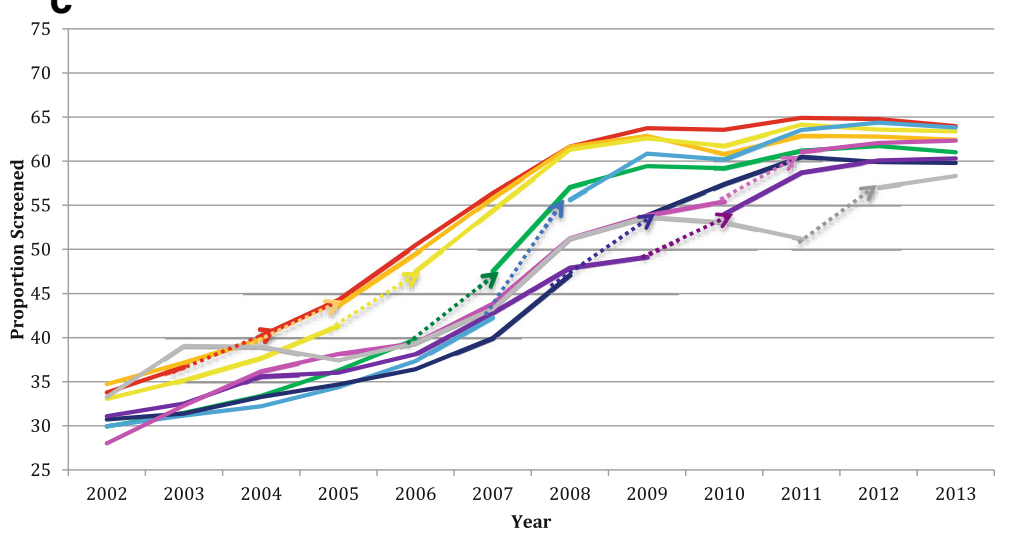

Fig. 2 Proportion of patients up-to-date stratified by year of transition from traditional fee-for-service to enhanced fee-for-service. Dotted arrows indicate the fiscal year of transition for practices. a Cervical cancer Screening. b Breast cancer screening. c Colorectal cancer screening

level or the trend over time. In contrast, the late adopters tended to have lower screening rates at the time of transition and a greater increase in screening rates after transition. Overall, there was a drop at the end of the study period in cervical cancer screening uptake.

Tables 3, 4, 5 show unadjusted and adjusted odds ratios produced from the mixed-effects logistic regression analyses, comparing the enhanced to traditional FFS models. Odds ratios are presented for each year, separately for patients who were foreign-born and who were long-term residents. One covariate, physician panel size, was excluded from the breast cancer screening model as the model failed to converge with this covariate included. This variable had a very small effect in the other two fully adjusted models. For cervical and breast cancer screening, odds ratios for immigrants were less than 1 in 
Table 3 Unadjusted and adjusted odds ratios comparing enhanced fee-for-service to traditional fee-for-service produced from the cervical cancer screening model

\begin{tabular}{|c|c|c|c|c|c|c|c|c|c|c|}
\hline & \multirow[t]{2}{*}{ Year } & \multicolumn{3}{|l|}{ Unadjusted } & \multicolumn{3}{|c|}{$\begin{array}{l}\text { Adjusted for Patient } \\
\text { Characteristics }\end{array}$} & \multicolumn{3}{|c|}{$\begin{array}{l}\text { Adjusted for Patient and Physician } \\
\text { Characteristics }\end{array}$} \\
\hline & & Odds Ratio & $95 \% \mathrm{Cl}$ & $p$-value & Odds Ratio & $95 \% \mathrm{Cl}$ & $p$-value & Odds Ratio & $95 \% \mathrm{Cl}$ & $p$-value \\
\hline \multicolumn{11}{|l|}{ Immigrants } \\
\hline \multirow{8}{*}{$\begin{array}{l}\text { Enhanced vs. traditional } \\
\text { fee-for-service }\end{array}$} & 2005 & 0.92 & $(0.90-0.93)$ & $<.0001$ & 0.89 & $(0.87-0.91)$ & $<.0001$ & 0.94 & $(0.92-0.96)$ & $<.0001$ \\
\hline & 2006 & 0.97 & $(0.96-0.98)$ & $<.0001$ & 0.95 & $(0.94-0.97)$ & $<.0001$ & 1.00 & $(0.98-1.01)$ & 0.567 \\
\hline & 2007 & 0.93 & $(0.98-1.01)$ & 0.404 & 0.98 & $(0.97-1.00)$ & 0.059 & 1.04 & $(1.03-1.06)$ & $<.0001$ \\
\hline & 2008 & 0.94 & $(0.92-0.96)$ & $<.0001$ & 0.95 & $(0.93-0.97)$ & $<.0001$ & 1.04 & $(1.02-1.06)$ & 0.001 \\
\hline & 2009 & 1.04 & $(1.01-1.06)$ & 0.004 & 1.08 & $(1.06-1.11)$ & $<.0001$ & 1.14 & $(1.11-1.17)$ & $<.0001$ \\
\hline & 2010 & 1.01 & $(0.98-1.04)$ & 0.503 & 1.07 & $(1.04-1.10)$ & $<.0001$ & 1.15 & $(1.12-1.19)$ & $<.0001$ \\
\hline & 2011 & 1.11 & $(1.07-1.16)$ & $<.0001$ & 1.16 & $(1.12-1.21)$ & $<.0001$ & 1.26 & $(1.21-1.31)$ & $<.0001$ \\
\hline & 2012 & 1.12 & $(1.08-1.17)$ & $<.0001$ & 1.26 & $(1.20-1.31)$ & $<.0001$ & 1.25 & $(1.19-1.30)$ & $<.0001$ \\
\hline \multicolumn{11}{|l|}{ Long-Term Residents } \\
\hline \multirow{8}{*}{$\begin{array}{l}\text { Enhanced vs. traditional } \\
\text { fee-for-service }\end{array}$} & 2005 & 1.04 & $(1.03-1.05)$ & $<.0001$ & 1.05 & $(1.04-1.06)$ & $<.0001$ & 1.05 & $(1.04-1.06)$ & $<.0001$ \\
\hline & 2006 & 1.02 & $(1.02-1.03)$ & $<.0001$ & 1.04 & $(1.03-1.05)$ & $<.0001$ & 1.06 & $(1.05-1.07)$ & $<.0001$ \\
\hline & 2007 & 1.08 & $(1.07-1.10)$ & $<.0001$ & 1.10 & $(1.08-1.11)$ & $<.0001$ & 1.13 & $(1.11-1.14)$ & $<.0001$ \\
\hline & 2008 & 1.09 & $(1.07-1.10)$ & $<.0001$ & 1.13 & $(1.11-1.14)$ & $<.0001$ & 1.17 & $(1.15-1.19)$ & $<.0001$ \\
\hline & 2009 & 1.18 & $(1.16-1.20)$ & $<.0001$ & 1.22 & $(1.19-1.24)$ & $<.0001$ & 1.20 & $(1.18-1.23)$ & $<.0001$ \\
\hline & 2010 & 1.18 & $(1.16-1.21)$ & $<.0001$ & 1.25 & $(1.22-1.28)$ & $<.0001$ & 1.28 & $(1.24-1.31)$ & $<.0001$ \\
\hline & 2011 & 1.12 & $(1.09-1.16)$ & $<.0001$ & 1.19 & $(1.15-1.23)$ & $<.0001$ & 1.24 & $(1.19-1.28)$ & $<.0001$ \\
\hline & 2012 & 1.11 & $(1.07-1.15)$ & $<.0001$ & 1.23 & $(1.18-1.27)$ & $<.0001$ & 1.20 & $(1.16-1.25)$ & $<.0001$ \\
\hline \multicolumn{11}{|l|}{ Ratios of Odds Ratios } \\
\hline \multirow{8}{*}{$\begin{array}{l}\text { Difference in enhanced vs. } \\
\text { traditional fee-for-service } \\
\text { between immigrants vs. } \\
\text { long-term residents }\end{array}$} & 2005 & 0.88 & $(0.86-0.90)$ & $<.0001$ & 0.85 & $(0.83-0.87)$ & $<.0001$ & 0.90 & $(0.88-0.92)$ & $<.0001$ \\
\hline & 2006 & 0.95 & $(0.93-0.96)$ & $<.0001$ & 0.92 & $(0.90-0.93)$ & $<.0001$ & 0.94 & $(0.92-0.96)$ & $<.0001$ \\
\hline & 2007 & 0.92 & $(0.90-0.94)$ & $<.0001$ & 0.90 & $(0.88-0.92)$ & $<.0001$ & 0.93 & $(0.91-0.95)$ & $<.0001$ \\
\hline & 2008 & 0.86 & $(0.84-0.88)$ & $<.0001$ & 0.84 & $(0.82-0.86)$ & $<.0001$ & 0.89 & $(0.86-0.91)$ & $<.0001$ \\
\hline & 2009 & 0.88 & $(0.85-0.91)$ & $<.0001$ & 0.89 & $(0.86-0.92)$ & $<.0001$ & 0.94 & $(0.92-0.97)$ & 0.000 \\
\hline & 2010 & 0.85 & $(0.22-0.89)$ & $<.0001$ & 0.86 & $(0.82-0.89)$ & $<.0001$ & 0.90 & $(0.87-0.94)$ & $<.0001$ \\
\hline & 2011 & 0.99 & $(0.95-1.04)$ & 0.794 & 0.98 & $(0.94-1.03)$ & 0.433 & 1.02 & $(0.97-1.07)$ & 0.477 \\
\hline & 2012 & 1.01 & $(0.96-1.07)$ & 0.607 & 1.02 & $(0.97-1.08)$ & 0.393 & 1.04 & $(0.98-1.10)$ & 0.180 \\
\hline
\end{tabular}

Ratios of odds ratios are also presented, with long-term residents and traditional fee-for-service serving as referent groups

earlier years (suggesting worse screening uptake in enhanced versus traditional FFS) and generally showed a steady increase to being greater than 1 in later years (suggesting better screening uptake in enhanced versus traditional FFS). Odds ratios were greater than 1 for patients who were long-term residents of the province throughout the study period suggesting better screening uptake in enhanced versus traditional FFS among long-term residents than among recent immigrants. For CRC screening, odds ratios for both immigrants and long-term residents were generally greater than 1 throughout the study period, suggesting better screening uptake in enhanced versus traditional FFS.

Tables 3, 4, 5 also display ratios of odds ratios. For most years (2005-2010), ratios of ratios were significantly less than 1 for all three cancer screening types, indicating that there was a widening of the screening gap between immigrants and long-term residents associated with transitions in those years. From 2011 onward, the ratios of ratios were no longer statistically significant, except for CRC screening where the ratios of both unadjusted and adjusted odds ratios changed direction and were significantly greater than 1 in 2012, indicating that by the end of the observation period, transition was associated with a significantly smaller screening gap for immigrants (ratio of odds ratios 1.199 [95\% CI 1.118-1.287] adjusted for patient and physician characteristics).

In 2002, when all physicians were still in traditional FFS, fully adjusted odds ratios comparing immigrant patients to long-term residents were 0.876 [95\% CI 0.868-0.884] 
Table 4 Unadjusted and adjusted odds ratios comparing enhanced fee-for-service to traditional fee-for-service produced from the breast cancer screening model

\begin{tabular}{|c|c|c|c|c|c|c|c|c|c|c|}
\hline & \multirow[t]{2}{*}{ Year } & \multicolumn{3}{|l|}{ Unadjusted } & \multicolumn{3}{|c|}{$\begin{array}{l}\text { Adjusted for Patient } \\
\text { Characteristics }\end{array}$} & \multicolumn{3}{|c|}{$\begin{array}{l}\text { Adjusted for Patient and Physician } \\
\text { Characteristics }\end{array}$} \\
\hline & & Odds Ratio & $95 \% \mathrm{Cl}$ & $\overline{p \text {-value }}$ & Odds Ratio & $95 \% \mathrm{Cl}$ & $p$-value & Odds Ratio & $95 \% \mathrm{Cl}$ & $p$-value \\
\hline \multicolumn{11}{|l|}{ Immigrants } \\
\hline \multirow{8}{*}{$\begin{array}{l}\text { Enhanced vs. traditional } \\
\text { fee-for-service }\end{array}$} & 2005 & 0.86 & $(0.83-0.90)$ & $<.0001$ & 0.86 & $(0.82-0.90)$ & $<.0001$ & 0.89 & $(0.85-0.93)$ & $<.0001$ \\
\hline & 2006 & 0.95 & $(0.92-0.98)$ & 0.0016 & 0.96 & $(0.93-0.99)$ & 0.0087 & 0.98 & $(0.94-1.01)$ & 0.1181 \\
\hline & 2007 & 0.98 & $(0.95-1.02)$ & 0.3024 & 0.98 & $(0.95-1.02)$ & 0.3391 & 1.02 & $(0.98-1.05)$ & 0.4424 \\
\hline & 2008 & 0.96 & $(0.92-1.00)$ & 0.0656 & 0.97 & $(0.92-1.01)$ & 0.1516 & 1.01 & $(0.97-1.06)$ & 0.5703 \\
\hline & 2009 & 0.99 & $(0.94-1.05)$ & 0.7257 & 1.02 & $(0.97-1.08)$ & 0.458 & 1.04 & $(0.98-1.10)$ & 0.238 \\
\hline & 2010 & 0.92 & $(0.86-0.98)$ & 0.0082 & 0.95 & $(0.89-1.01)$ & 0.0933 & 1.00 & $(0.93-1.06)$ & 0.9135 \\
\hline & 2011 & 1.09 & $(1.01-1.18)$ & 0.0229 & 1.14 & $(1.06-1.23)$ & 0.0008 & 1.21 & $(1.12-1.31)$ & $<.0001$ \\
\hline & 2012 & 1.21 & $(1.11-1.32)$ & $<.0001$ & 1.30 & $(1.19-1.42)$ & $<.0001$ & 1.29 & $(1.18-1.40)$ & $<.0001$ \\
\hline \multicolumn{11}{|l|}{ Long-Term Residents } \\
\hline \multirow{8}{*}{$\begin{array}{l}\text { Enhanced vs. traditional } \\
\text { fee-for-service }\end{array}$} & 2005 & 1.01 & $(1.00-1.02)$ & 0.1411 & 1.01 & $(1.00-1.03)$ & 0.0435 & 1.02 & $(1.00-1.03)$ & 0.032 \\
\hline & 2006 & 1.04 & $(1.02-1.05)$ & $<.0001$ & 1.04 & $(1.03-1.05)$ & $<.0001$ & 1.05 & $(1.04-1.07)$ & $<.0001$ \\
\hline & 2007 & 1.09 & $(1.07-1.11)$ & $<.0001$ & 1.09 & $(1.07-1.11)$ & $<.0001$ & 1.11 & $(1.09-1.13)$ & $<.0001$ \\
\hline & 2008 & 1.13 & $(1.10-1.16)$ & $<.0001$ & 1.14 & $(1.11-1.17)$ & $<.0001$ & 1.17 & $(1.14-1.20)$ & $<.0001$ \\
\hline & 2009 & 1.19 & $(1.15-1.22)$ & $<.0001$ & 1.20 & $(1.17-1.24)$ & $<.0001$ & 1.19 & $(1.15-1.23)$ & $<.0001$ \\
\hline & 2010 & 1.16 & $(1.11-1.21)$ & $<.0001$ & 1.17 & $(1.13-1.22)$ & $<.0001$ & 1.19 & $(1.14-1.24)$ & $<.0001$ \\
\hline & 2011 & 1.20 & $(1.13-1.26)$ & $<.0001$ & 1.21 & $(1.15-1.27)$ & $<.0001$ & 1.25 & $(1.18-1.31)$ & $<.0001$ \\
\hline & 2012 & 1.14 & $(1.07-1.21)$ & $<.0001$ & 1.19 & $(1.12-1.26)$ & $<.0001$ & 1.17 & $(1.10-1.24)$ & $<.0001$ \\
\hline \multicolumn{11}{|l|}{ Ratios of Odds Ratios } \\
\hline \multirow{8}{*}{$\begin{array}{l}\text { Difference in enhanced vs. } \\
\text { traditional fee-for-service } \\
\text { between immigrants vs. } \\
\text { long-term residents }\end{array}$} & 2005 & 0.85 & $(0.82-0.89)$ & $<.0001$ & 0.85 & $(0.81-0.89)$ & $<.0001$ & 0.87 & $(0.84-0.91)$ & $<.0001$ \\
\hline & 2006 & 0.92 & $(0.89-0.95)$ & $<.0001$ & 0.92 & $(0.89-0.95)$ & $<.0001$ & 0.93 & $(0.90-0.96)$ & $<.0001$ \\
\hline & 2007 & 0.90 & $(0.86-0.94)$ & $<.0001$ & 0.90 & $(0.87-0.94)$ & $<.0001$ & 0.92 & $(0.88-0.96)$ & $<.0001$ \\
\hline & 2008 & 0.85 & $(0.81-0.89)$ & $<.0001$ & 0.85 & $(0.80-0.89)$ & $<.0001$ & 0.87 & $(0.82-0.91)$ & $<.0001$ \\
\hline & 2009 & 0.83 & $(0.78-0.89)$ & $<.0001$ & 0.85 & $(0.80-0.90)$ & $<.0001$ & 0.87 & $(0.82-0.93)$ & $<.0001$ \\
\hline & 2010 & 0.79 & $(0.73-0.85)$ & $<.0001$ & 0.81 & $(0.75-0.87)$ & $<.0001$ & 0.84 & $(0.78-0.90)$ & $<.0001$ \\
\hline & 2011 & 0.91 & $(0.84-1.00)$ & 0.050 & 0.95 & $(0.86-1.03)$ & 0.218 & 0.97 & $(0.89-1.07)$ & 0.5267 \\
\hline & 2012 & 1.06 & $(0.96-1.18)$ & 0.273 & 1.10 & $(0.99-1.22)$ & 0.089 & 1.10 & $(0.99-1.22)$ & 0.0803 \\
\hline
\end{tabular}

Ratios of odds ratios are also presented, with long-term residents and traditional fee-for-service serving as referent groups

for cervical screening, 0.639 [95\% confidence interval $0.626-0.653]$ for breast screening, and 0.728 [95\% CI 0.716-0.740] for CRC screening. In 2013, at which point all physicians had transitioned to enhanced FFS, fully adjusted odds ratios comparing immigrant to long-term residents had risen to 0.908 [95\% CI 0.900-0.916] for cervical screening, 0.913 [95\% CI 0.898-0.927] for breast screening, and 0.881 [95\% confidence interval $0.872-$ 0.890] for CRC screening (data not shown).

Tables 6, 7, 8 show both unadjusted and adjusted odds ratios produced from the regression analyses, comparing patients living in the lowest and highest income quintiles and stratified by year and model type (data for income quintiles Q2-Q4 not shown). For all three types of cancer screening, odds ratios comparing enhanced to traditional
FFS were generally greater than 1 for patients in both Q1 and Q5, indicating better screening uptake in enhanced versus traditional models.

Tables 6, 7, 8 also show the ratios of odds ratios comparing differences between patients living in the lowest and highest income quintiles between enhanced FFS and traditional FFS models. From 2005 to 2011, ratios of ratios were significantly less than 1 for breast and cervical cancer screening, indicating that the transition to enhanced FFS was associated with a widening of screening gaps between people of lowest and highest income. In 2012, ratios of ratios were no longer significantly different than 1 for breast cancer screening (ratio of odds ratios 0.966 [95\% confidence interval 0.824-1.133] adjusted for patient and physician characteristics). For 
Table 5 Unadjusted and adjusted odds ratios comparing enhanced fee-for-service to traditional fee-for-service produced from the colorectal cancer screening model

\begin{tabular}{|c|c|c|c|c|c|c|c|c|c|c|}
\hline & \multirow[t]{2}{*}{ Year } & \multicolumn{3}{|l|}{ Unadjusted } & \multicolumn{3}{|c|}{$\begin{array}{l}\text { Adjusted for Patient } \\
\text { Characteristics }\end{array}$} & \multicolumn{3}{|c|}{$\begin{array}{l}\text { Adjusted for Patient and Physician } \\
\text { Characteristics }\end{array}$} \\
\hline & & Odds Ratio & $95 \% \mathrm{Cl}$ & $\overline{p \text {-value }}$ & Odds Ratio & $95 \% \mathrm{Cl}$ & $\overline{p \text {-value }}$ & Odds Ratio & $95 \% \mathrm{Cl}$ & $p$-value \\
\hline \multicolumn{11}{|l|}{ Immigrants } \\
\hline \multirow{8}{*}{$\begin{array}{l}\text { Enhanced vs. traditional } \\
\text { fee-for-service }\end{array}$} & 2005 & 0.91 & $(0.89-0.94)$ & $<.0001$ & 0.91 & $(0.88-0.94)$ & $<.0001$ & 0.94 & $(0.91-0.97)$ & $<.0001$ \\
\hline & 2006 & 1.02 & $(0.99-1.04)$ & 0.1809 & 1.03 & $(1.01-1.05)$ & 0.0074 & 1.04 & $(1.01-1.06)$ & 0.0021 \\
\hline & 2007 & 1.21 & $(1.18-1.24)$ & $<.0001$ & 1.22 & $(1.19-1.26)$ & $<.0001$ & 1.24 & $(1.21-1.28)$ & $<.0001$ \\
\hline & 2008 & 1.13 & $(1.09-1.16)$ & $<.0001$ & 1.15 & $(1.11-1.19)$ & $<.0001$ & 1.19 & $(1.15-1.23)$ & $<.0001$ \\
\hline & 2009 & 1.19 & $(1.14-1.23)$ & $<.0001$ & 1.23 & $(1.19-1.28)$ & $<.0001$ & 1.23 & $(1.19-1.28)$ & $<.0001$ \\
\hline & 2010 & 0.99 & $(0.95-1.04)$ & 0.7596 & 1.03 & $(0.98-1.07)$ & 0.2438 & 1.06 & $(1.02-1.11)$ & 0.007 \\
\hline & 2011 & 1.06 & $(1.01-1.11)$ & 0.0319 & 1.09 & $(1.04-1.15)$ & 0.0012 & 1.13 & $(1.07-1.19)$ & $<.0001$ \\
\hline & 2012 & 1.25 & $(1.18-1.32)$ & $<.0001$ & 1.38 & $(1.31-1.47)$ & $<.0001$ & 1.38 & $(1.30-1.57)$ & $<.0001$ \\
\hline \multicolumn{11}{|l|}{ Long-Term Residents } \\
\hline \multirow{8}{*}{$\begin{array}{l}\text { Enhanced vs. traditional } \\
\text { fee-for-service }\end{array}$} & 2005 & 1.00 & $(0.99-1.01)$ & 0.5301 & 1.00 & $(0.99-1.01)$ & 0.528 & 1.00 & $(1.00-1.01)$ & 0.4123 \\
\hline & 2006 & 1.09 & $(1.08-1.10)$ & $<.0001$ & 1.10 & $(1.09-1.10)$ & $<.0001$ & 1.10 & $(1.09-1.11)$ & $<.0001$ \\
\hline & 2007 & 1.25 & $(1.23-1.26)$ & $<.0001$ & 1.26 & $(1.24-1.27)$ & $<.0001$ & 1.27 & $(1.25-1.28)$ & $<.0001$ \\
\hline & 2008 & 1.20 & $(1.18-1.22)$ & $<.0001$ & 1.23 & $(1.21-1.25)$ & $<.0001$ & 1.25 & $(1.23-1.27)$ & $<.0001$ \\
\hline & 2009 & 1.27 & $(1.25-1.30)$ & $<.0001$ & 1.31 & $(1.28-1.34)$ & $<.0001$ & 1.29 & $(1.26-1.32)$ & $<.0001$ \\
\hline & 2010 & 1.15 & $(1.12-1.18)$ & $<.0001$ & 1.17 & $(1.14-1.20)$ & $<.0001$ & 1.19 & $(1.16-1.22)$ & $<.0001$ \\
\hline & 2011 & 1.10 & $(1.06-1.14)$ & $<.0001$ & 1.11 & $(1.07-1.15)$ & $<.0001$ & 1.14 & $(1.10-1.18)$ & $<.0001$ \\
\hline & 2012 & 1.09 & $(1.05-1.14)$ & $<.0001$ & 1.17 & $(1.12-1.21)$ & $<.0001$ & 1.15 & $(1.11-1.20)$ & $<.0001$ \\
\hline \multicolumn{11}{|l|}{ Ratios of Odds Ratios } \\
\hline \multirow{8}{*}{$\begin{array}{l}\text { Difference in enhanced vs. } \\
\text { traditional fee-for-service } \\
\text { between immigrants vs. } \\
\text { long-term residents }\end{array}$} & 2005 & 0.92 & $(0.89-0.94)$ & $<.0001$ & 0.91 & $(0.88-0.94)$ & $<.0001$ & 0.94 & $(0.91-0.96)$ & $<.0001$ \\
\hline & 2006 & 0.93 & $(0.91-0.95)$ & $<.0001$ & 0.94 & $(0.92-0.963)$ & $<.0001$ & 0.94 & $(0.92-0.96)$ & $<.0001$ \\
\hline & 2007 & 0.97 & $(0.95-1.00)$ & 0.0508 & 0.97 & $(0.95-1.00)$ & 0.0659 & 0.98 & $(0.95-1.01)$ & 0.1798 \\
\hline & 2008 & 0.94 & $(0.90-0.97)$ & 0.0002 & 0.93 & $(0.90-0.97)$ & $<.0001$ & 0.95 & $(0.91-0.98)$ & 0.0031 \\
\hline & 2009 & 0.93 & $(0.89-0.97)$ & 0.0009 & 0.94 & $(0.90-0.98)$ & 0.0061 & 0.96 & $(0.92-1.00)$ & 0.037 \\
\hline & 2010 & 0.87 & $(0.82-0.91)$ & $<.0001$ & 0.88 & $(0.84-0.93)$ & $<.0001$ & 0.89 & $(0.85-0.94)$ & $<.0001$ \\
\hline & 2011 & 0.96 & $(0.90-1.02)$ & 0.1821 & 0.99 & $(0.93-1.05)$ & 0.671 & 0.99 & $(0.93-1.06)$ & 0.8325 \\
\hline & 2012 & 1.14 & $(1.07-1.22)$ & 0.0001 & 1.19 & $(1.11-1.27)$ & $<.0001$ & 1.20 & $(1.12-1.29)$ & $<.0001$ \\
\hline
\end{tabular}

Ratios of odds ratios are also presented, with long-term residents and traditional fee-for-service serving as referent groups

CRC screening, in contrast, ratios of odds ratios varied over the years. However, the transition to enhanced FFS tended to either be non-significant or to be associated with a widening of the gap in most years.

In 2002, when all physicians were still in traditional FFS practices, adjusted odds ratios comparing the lowest income to the highest income patients were 0.720 [95\% confidence interval 0.712-0.728] for cervical screening 0.651 [95\% confidence interval $0.639-0.663$ ] for breast screening, and 0.817 [95\% confidence interval 0.8060.827] for CRC screening. In 2013, these values were 0.691 [95\% confidence interval 0.682-0.701] for cervical cancer screening, 0.707 [95\% confidence interval 0.6920.723] for breast screening and dropped to 0.638 [95\% confidence interval 0.629-0.648] for CRC screening.

\section{Discussion}

We conducted a population-based longitudinal analysis from 2002 to 2013 among a group of family physicians that all eventually transitioned to enhanced FFS from traditional FFS in Ontario. We found that this transition of primary care model type was generally associated with increased screening uptake for both immigrants and long-terms residents, and for people in both the lowest and highest income quintiles. However, the transition appeared to be less beneficial for more disadvantaged groups, as it was associated with a widening of screening inequities for foreign-born and low-income patients, with the exception of the most recent years. Although the early adopters of the enhanced model had better overall screening rates to begin with, and continued this performance 
Table 6 Unadjusted and adjusted odds ratios comparing enhanced to traditional fee-for-service produced from the cervical cancer screening model

\begin{tabular}{|c|c|c|c|c|c|c|c|c|c|c|}
\hline & \multirow[t]{2}{*}{ Year } & \multicolumn{3}{|l|}{ Unadjusted } & \multicolumn{3}{|c|}{$\begin{array}{l}\text { Adjusted for Patient } \\
\text { Characteristics }\end{array}$} & \multicolumn{3}{|c|}{$\begin{array}{l}\text { Adjusted for Patient and Physician } \\
\text { Characteristics }\end{array}$} \\
\hline & & Odds Ratio & $95 \% \mathrm{Cl}$ & $p$-value & Odds Ratio & $95 \% \mathrm{Cl}$ & $p$-value & Odds Ratio & $95 \% \mathrm{Cl}$ & $p$-value \\
\hline \multicolumn{11}{|l|}{ Income Q1 (lowest) } \\
\hline \multirow{8}{*}{$\begin{array}{l}\text { Enhanced vs. traditional } \\
\text { fee-for-service }\end{array}$} & 2005 & 0.97 & $(0.96-0.99)$ & 0.000 & 0.96 & $(0.95-0.98)$ & $<.0001$ & 0.98 & $(0.97-1.00)$ & 0.0231 \\
\hline & 2006 & 0.99 & $(0.98-1.00)$ & 0.080 & 0.98 & $(0.96-0.99)$ & 0.0008 & 1.00 & $(0.99-1.02)$ & 0.7417 \\
\hline & 2007 & 1.03 & $(1.01-1.05)$ & 0.004 & 1.02 & $(1.00-1.04)$ & 0.0271 & 1.06 & $(1.04-1.08)$ & $<.0001$ \\
\hline & 2008 & 0.98 & $(0.96-1.01)$ & 0.145 & 0.99 & $(0.97-1.0)$ & 0.649 & 1.04 & $(1.02-1.07)$ & 0.001 \\
\hline & 2009 & 1.10 & $(1.07-1.14)$ & $<.0001$ & 1.14 & $(1.10-1.17)$ & $<.0001$ & 1.16 & $(1.13-1.20)$ & $<.0001$ \\
\hline & 2010 & 1.04 & $(1.00-1.08)$ & 0.028 & 1.10 & $(1.06-1.14)$ & $<.0001$ & 1.16 & $(1.11-1.20)$ & $<.0001$ \\
\hline & 2011 & 1.04 & $(1.00-1.09)$ & 0.082 & 1.09 & $(1.04-1.15)$ & 0.0004 & 1.19 & $(1.31-1.25)$ & $<.0001$ \\
\hline & 2012 & 1.08 & $(1.02-1.14)$ & 0.006 & 1.21 & $(1.14-1.28)$ & $<.0001$ & 1.20 & $(1.13-1.27)$ & $<.0001$ \\
\hline \multicolumn{11}{|l|}{ Income Q5 (highest) } \\
\hline \multirow{8}{*}{$\begin{array}{l}\text { Enhanced vs. traditional } \\
\text { fee-for-service }\end{array}$} & 2005 & 1.06 & $(1.04-1.07)$ & $<.0001$ & 1.07 & $(1.05-1.09)$ & $<.0001$ & 1.06 & $(1.05-1.08)$ & $<.0001$ \\
\hline & 2006 & 1.04 & $(1.03-1.06)$ & $<.0001$ & 1.06 & $(1.05-1.08)$ & $<.0001$ & 1.09 & $(1.08-1.11)$ & $<.0001$ \\
\hline & 2007 & 1.15 & $(1.13-1.18)$ & $<.0001$ & 1.18 & $(1.15-1.21)$ & $<.0001$ & 1.20 & $(1.17-1.23)$ & $<.0001$ \\
\hline & 2008 & 1.15 & $(1.12-1.19)$ & $<.0001$ & 1.20 & $(1.17-1.24)$ & $<.0001$ & 1.26 & $(1.22-1.30)$ & $<.0001$ \\
\hline & 2009 & 1.18 & $(1.14-1.22)$ & $<.0001$ & 1.24 & $(1.20-1.29)$ & $<.0001$ & 1.24 & $(1.20-1.29)$ & $<.0001$ \\
\hline & 2010 & 1.26 & $(1.20-1.32)$ & $<.0001$ & 1.35 & $(1.29-1.42)$ & $<.0001$ & 1.38 & $(1.31-1.44)$ & $<.0001$ \\
\hline & 2011 & 1.21 & $(1.15-1.29)$ & $<.0001$ & 1.33 & $(1.25-1.41)$ & $<.0001$ & 1.37 & $(1.29-1.45)$ & $<.0001$ \\
\hline & 2012 & 1.17 & $(1.10-1.25)$ & $<.0001$ & 1.33 & $(1.24-1.42)$ & $<.0001$ & 1.31 & $(1.23-1.41)$ & $<.0001$ \\
\hline \multicolumn{11}{|l|}{ Ratios of Odds Ratios } \\
\hline \multirow{8}{*}{$\begin{array}{l}\text { Difference in enhanced vs. } \\
\text { traditional fee-for-service } \\
\text { between Q1 vs. Q5 }\end{array}$} & 2005 & 0.92 & $(0.90-0.94)$ & $<.0001$ & 0.90 & $(0.88-0.92)$ & $<.0001$ & 0.92 & $(0.90-0.95)$ & $<.0001$ \\
\hline & 2006 & 0.95 & $(0.93-0.97)$ & $<.0001$ & 0.92 & $(0.90-0.94)$ & $<.0001$ & 0.92 & $(0.90-0.94)$ & $<.0001$ \\
\hline & 2007 & 0.89 & $(0.87-0.92)$ & $<.0001$ & 0.87 & $(0.84-0.89)$ & $<.0001$ & 0.88 & $(0.86-0.909)$ & $<.0001$ \\
\hline & 2008 & 0.85 & $(0.82-0.89)$ & $<.0001$ & 0.83 & $(0.79-0.86)$ & $<.0001$ & 0.83 & $(0.80-0.86)$ & $<.0001$ \\
\hline & 2009 & 0.94 & $(0.90-0.98)$ & 0.007 & 0.92 & $(0.87-0.96)$ & 0.000 & 0.94 & $(0.89-0.98)$ & 0.0059 \\
\hline & 2010 & 0.83 & $(0.78-0.88)$ & $<.0001$ & 0.81 & $(0.76-0.86)$ & $<.0001$ & 0.84 & $(0.79-0.89)$ & $<.0001$ \\
\hline & 2011 & 0.86 & $(0.80-0.92)$ & $<.0001$ & 0.82 & $(0.76-0.89)$ & $<.0001$ & 0.87 & $(0.81-0.94)$ & 0.0003 \\
\hline & 2012 & 0.92 & $(0.85-1.01)$ & 0.064 & 0.91 & $(0.84-0.99)$ & 0.032 & 0.91 & $(0.83-0.99)$ & 0.0353 \\
\hline
\end{tabular}

Results for Q2-Q4 not shown. Ratios of odds ratios are also presented, with Q5 and traditional fee-for-service serving as referent groups

after transition, screening inequities were worse for patients of these physicians after adjusting for certain patient and physician characteristics. In contrast, the latest adopters tended to have lower overall screening rates but smaller screening inequities. These physicians saw an improvement in their overall screening with the shift to enhanced FFS. Of note, overall screening for CRC rose dramatically over time but this appears to be due to secular trends and not to the enhanced FFS transition [43].

It is likely that physicians with certain characteristics, or those treating patients of certain characteristics, were more likely to find the new models appealing and therefore to transition in earlier years. New models provided financial rewards for having high overall cancer screening rates, and did not incorporate equity measures into these rewards. It is not possible to determine the role that preventive care bonuses played for the physicians in this study. However, a previous Ontario study demonstrated that family physicians self-selected into the different model types, and suggested that physicians who had more patient visits, had a greater proportion of immigrants in their roster, and had patients with a higher level of need were more likely to select traditional FFS than enhanced FFS [44]. Of note, all the physicians in our study eventually transitioned to enhanced FFS and the screening patterns of those physicians who never transitioned, or who transitioned to other model types, are not known.

Our findings are comparable to other literature that has explored the impacts of primary care reform in Ontario on screening and preventive care. Kiran et al. found that in the year after financial incentives were 
Table 7 Unadjusted and adjusted odds ratios comparing enhanced to traditional fee-for-service produced from the breast cancer screening model

\begin{tabular}{|c|c|c|c|c|c|c|c|c|c|c|}
\hline & \multirow[t]{2}{*}{ Year } & \multicolumn{3}{|l|}{ Unadjusted } & \multicolumn{3}{|c|}{$\begin{array}{l}\text { Adjusted for Patient } \\
\text { Characteristics }\end{array}$} & \multicolumn{3}{|c|}{$\begin{array}{l}\text { Adjusted for Patient and Physician } \\
\text { Characteristics }\end{array}$} \\
\hline & & Odds Ratio & $95 \% \mathrm{Cl}$ & $p$-value & Odds Ratio & $95 \% \mathrm{Cl}$ & $p$-value & Odds Ratio & $95 \% \mathrm{Cl}$ & $p$-value \\
\hline \multicolumn{11}{|l|}{ Income Q1 (lowest) } \\
\hline \multirow{8}{*}{$\begin{array}{l}\text { Enhanced vs. traditional } \\
\text { fee-for-service }\end{array}$} & 2005 & 0.97 & $(0.95-1.00)$ & 0.0438 & 0.97 & $(0.94-0.99)$ & 0.0123 & 0.97 & $(0.95-1.00)$ & 0.0646 \\
\hline & 2006 & 1.02 & $(1.00-1.04)$ & 0.1186 & 1.01 & $(0.98-1.03)$ & 0.5442 & 1.02 & $(0.99-1.04)$ & 0.2084 \\
\hline & 2007 & 1.05 & $(1.01-1.08)$ & 0.0141 & 1.03 & $(0.99-1.06)$ & 0.1498 & 1.04 & $(1.01-1.08)$ & 0.0165 \\
\hline & 2008 & 1.06 & $(1.01-1.11)$ & 0.0169 & 1.06 & $(1.01-1.11)$ & 0.0187 & 1.08 & $(1.03-1.14)$ & 0.0009 \\
\hline & 2009 & 1.07 & $(1.01-1.14)$ & 0.0147 & 1.10 & $(1.04-1.16)$ & 0.0017 & 1.10 & $(1.04-1.16)$ & 0.0015 \\
\hline & 2010 & 0.99 & $(0.92-1.06)$ & 0.8048 & 1.01 & $(0.94-1.09)$ & 0.7935 & 1.04 & $(0.97-1.12)$ & 0.2686 \\
\hline & 2011 & 1.07 & $(0.98-1.17)$ & 0.1351 & 1.09 & $(0.99-1.19)$ & 0.0711 & 1.14 & $(1.04-1.25)$ & 0.0043 \\
\hline & 2012 & 1.11 & $(1.00-1.23)$ & 0.0551 & 1.16 & $(1.04-1.29)$ & 0.0058 & 1.15 & $(1.03-1.28)$ & 0.0117 \\
\hline \multicolumn{11}{|l|}{ Income Q5 (highest) } \\
\hline \multirow{8}{*}{$\begin{array}{l}\text { Enhanced vs. traditional } \\
\text { fee-for-service }\end{array}$} & 2005 & 1.03 & $(1.00-1.05)$ & 0.027 & 1.04 & $(1.01-1.06)$ & 0.0033 & 1.03 & $(1.01-1.06)$ & 0.0135 \\
\hline & 2006 & 1.03 & $(1.01-1.05)$ & 0.0167 & 1.04 & $(1.02-1.07)$ & 0.0002 & 1.06 & $(1.03-1.08)$ & $<.0001$ \\
\hline & 2007 & 1.11 & $(1.07-1.15)$ & $<.0001$ & 1.11 & $(1.07-1.16)$ & $<.0001$ & 1.13 & $(1.09-1.17)$ & $<.0001$ \\
\hline & 2008 & 1.14 & $(1.09-1.2)$ & $<.0001$ & 1.15 & $(1.09-1.21)$ & $<.0001$ & 1.18 & $(1.12-1.24)$ & $<.0001$ \\
\hline & 2009 & 1.20 & $(1.13-1.28)$ & $<.0001$ & 1.22 & $(1.15-1.30)$ & $<.0001$ & 1.21 & $(1.14-1.29)$ & $<.0001$ \\
\hline & 2010 & 1.22 & $(1.13-1.32)$ & $<.0001$ & 1.24 & $(1.14-1.34)$ & $<.0001$ & 1.25 & $(1.15-1.36)$ & $<.0001$ \\
\hline & 2011 & 1.26 & $(1.14-1.40)$ & $<.0001$ & 1.29 & $(1.17-1.43)$ & $<.0001$ & 1.33 & $(1.20-1.47)$ & $<.0001$ \\
\hline & 2012 & 1.14 & $(1.02-1.28)$ & 0.0276 & 1.19 & $(1.06-1.35)$ & 0.0035 & 1.19 & $(1.05-1.34)$ & 0.005 \\
\hline \multicolumn{11}{|l|}{ Ratios of Odds Ratios } \\
\hline \multirow{8}{*}{$\begin{array}{l}\text { Difference in enhanced vs. } \\
\text { traditional fee-for-service } \\
\text { between Q1 vs. Q5 }\end{array}$} & 2005 & 0.95 & $(0.91-0.98)$ & 0.002 & 0.93 & $(0.90-0.97)$ & $<.0001$ & 0.94 & $(0.91-0.98)$ & 0.002 \\
\hline & 2006 & 0.99 & $(0.96-1.02)$ & 0.594 & 0.97 & $(0.94-1.00)$ & 0.032 & 0.96 & $(0.93-0.99)$ & 0.014 \\
\hline & 2007 & 0.94 & $(0.90-0.99)$ & 0.018 & 0.92 & $(0.88-0.97)$ & 0.002 & 0.93 & $(0.88-0.97)$ & 0.003 \\
\hline & 2008 & 0.93 & $(0.87-0.99)$ & 0.029 & 0.92 & $(0.86-0.99)$ & 0.018 & 0.92 & $(0.86-0.98)$ & 0.016 \\
\hline & 2009 & 0.89 & $(0.82-0.97)$ & 0.006 & 0.90 & $(0.83-0.98)$ & 0.011 & 0.91 & $(0.84-0.99)$ & 0.020 \\
\hline & 2010 & 0.81 & $(0.73-0.90)$ & 0.000 & 0.82 & $(0.73-0.91)$ & 0.000 & 0.83 & $(0.75-0.93)$ & 0.001 \\
\hline & 2011 & 0.85 & $(0.74-0.97)$ & 0.014 & 0.84 & $(0.74-0.96)$ & 0.011 & 0.86 & $(0.75-0.98)$ & 0.027 \\
\hline & 2012 & 0.97 & $(0.83-1.14)$ & 0.716 & 0.97 & $(0.83-1.14)$ & 0.734 & 0.97 & $(0.82-1.13)$ & 0.671 \\
\hline
\end{tabular}

Results for Q2-Q4 not shown. Ratios of odds ratios are also presented, with Q5 and traditional fee-for-service serving as referent groups

introduced to primary care, there were no significant changes in breast and cervical screening and only a small increase in CRC screening; income-related inequalities persisted for all three cancer screening types [32]. Patients enrolled to one of the new primary care models were more likely to receive screening than other patients, even before the introduction of financial incentives [32]. Dahrouge et al. found that no particular model type was clearly associated with superior preventive care [45]. Physician characteristics, such as gender and patient load, were more predictive of performance [45]. In one cross-sectional analysis conducted in 2011, there were minimal differences in cancer screening between primary care model types, including enhanced FFS and capitation models [46]. Although primary care reform has not had a clear effect on screening and equity, the literature does suggest that immigrant and low-income patients who are in some type of PEM have higher screening rates than those who are not [15, 16, 21, 47]. However, a recent Ontario study showed that patients who are foreign-born and living in low-income neighbourhoods were more likely to still be in traditional FFS practices [48].

This study has several limitations. First, current administrative data do not include Pap tests interpreted in hospital laboratories and thus may underestimate cervical cancer screening. However, we expect that relatively few screening Pap tests are interpreted in the hospital setting and have no reason to believe that this would differ by primary care model type. Second, the IRCC database is not $100 \%$ sensitive, and does not include immigrants who moved to other provinces in Canada before moving to Ontario or who could not be probabilistically linked. 
Table 8 Unadjusted and adjusted odds ratios comparing enhanced to traditional fee-for-service produced from the CRC screening model

\begin{tabular}{|c|c|c|c|c|c|c|c|c|c|c|}
\hline & \multirow[t]{2}{*}{ Year } & \multicolumn{3}{|l|}{ Unadjusted } & \multicolumn{3}{|c|}{$\begin{array}{l}\text { Adjusted for Patient } \\
\text { Characteristics }\end{array}$} & \multicolumn{3}{|c|}{$\begin{array}{l}\text { Adjusted for Patient and Physician } \\
\text { Characteristics }\end{array}$} \\
\hline & & Odds Ratio & $95 \% \mathrm{Cl}$ & $p$-value & Odds Ratio & $95 \% \mathrm{Cl}$ & $p$-value & Odds Ratio & $95 \% \mathrm{Cl}$ & $p$-value \\
\hline \multicolumn{11}{|l|}{ Income Q1 (lowest) } \\
\hline \multirow{8}{*}{$\begin{array}{l}\text { Enhanced vs. traditional } \\
\text { fee-for-service }\end{array}$} & 2005 & 1.00 & $(0.98-1.02)$ & 0.677 & 0.99 & $(0.97-1.01)$ & 0.283 & 1.00 & $(0.98-1.02)$ & 0.698 \\
\hline & 2006 & 1.12 & $(1.10-1.14)$ & $<.0001$ & 1.11 & $(1.09-1.13)$ & $<.0001$ & 1.11 & $(1.10-1.13)$ & $<.0001$ \\
\hline & 2007 & 1.24 & $(1.21-1.27)$ & $<.0001$ & 1.23 & $(1.20-1.26)$ & $<.0001$ & 1.24 & $(1.21-1.27)$ & $<.0001$ \\
\hline & 2008 & 1.15 & $(1.12-1.19)$ & $<.0001$ & 1.16 & $(1.13-1.20)$ & $<.0001$ & 1.18 & $(1.14-1.22)$ & $<.0001$ \\
\hline & 2009 & 1.26 & $(1.22-1.31)$ & $<.0001$ & 1.30 & $(1.25-1.35)$ & $<.0001$ & 1.29 & $(1.24-1.34)$ & $<.0001$ \\
\hline & 2010 & 1.05 & $(1.00-1.10)$ & 0.048 & 1.07 & $(1.02-1.12)$ & 0.009 & 1.10 & $(1.04-1.15)$ & 0.000 \\
\hline & 2011 & 1.01 & $(0.96-1.08)$ & 0.655 & 1.01 & $(0.95-1.08)$ & 0.747 & 1.05 & $(0.99-1.12)$ & 0.115 \\
\hline & 2012 & 1.12 & $(1.05-1.20)$ & 0.001 & 1.20 & $(1.12-1.29)$ & $<.0001$ & 1.20 & $(1.12-1.29)$ & $<.0001$ \\
\hline \multicolumn{11}{|l|}{ Income Q5 (highest) } \\
\hline \multirow{8}{*}{$\begin{array}{l}\text { Enhanced vs. traditional } \\
\text { fee-for-service }\end{array}$} & 2005 & 0.99 & $(0.98-1.01)$ & 0.190 & 1.00 & $(0.99-1.02)$ & 0.895 & 1.00 & $(0.98-1.01)$ & 0.853 \\
\hline & 2006 & 1.05 & $(1.04-1.07)$ & $<.0001$ & 1.07 & $(1.05-1.08)$ & $<.0001$ & 1.08 & $(1.06-1.09)$ & $<.0001$ \\
\hline & 2007 & 1.24 & $(1.21-1.26)$ & $<.0001$ & 1.25 & $(1.22-1.28)$ & $<.0001$ & 1.26 & $(1.23-1.29)$ & $<.0001$ \\
\hline & 2008 & 1.22 & $(1.18-1.26)$ & $<.0001$ & 1.25 & $(1.21-1.29)$ & $<.0001$ & 1.28 & $(1.24-1.32)$ & $<.0001$ \\
\hline & 2009 & 1.26 & $(1.21-1.30)$ & $<.0001$ & 1.30 & $(1.25-1.35)$ & $<.0001$ & 1.28 & $(1.24-1.34)$ & $<.0001$ \\
\hline & 2010 & 1.19 & $(1.13-1.25)$ & $<.0001$ & 1.22 & $(1.15-1.28)$ & $<.0001$ & 1.24 & $(1.17-1.31)$ & $<.0001$ \\
\hline & 2011 & 1.21 & $(1.13-1.30)$ & $<.0001$ & 1.23 & $(1.15-1.32)$ & $<.0001$ & 1.27 & $(1.18-1.36)$ & $<.0001$ \\
\hline & 2012 & 1.17 & $(1.09-1.27)$ & $<.0001$ & 1.25 & $(1.16-1.36)$ & $<.0001$ & 1.26 & $(1.16-1.36)$ & $<.0001$ \\
\hline \multicolumn{11}{|l|}{ Ratios of Odds Ratios } \\
\hline \multirow{8}{*}{$\begin{array}{l}\text { Difference in enhanced vs. } \\
\text { traditional fee-for-service } \\
\text { between Q1 vs. Q5 }\end{array}$} & 2005 & 1.01 & $(0.98-1.03)$ & 0.619 & 0.99 & $(0.97-1.01)$ & 0.344 & 1.00 & $(0.97-1.02)$ & 0.847 \\
\hline & 2006 & 1.06 & $(1.04-1.09)$ & $<.0001$ & 1.04 & $(1.02-1.06)$ & 0.000 & 1.04 & $(1.01-1.06)$ & 0.001 \\
\hline & 2007 & 1.00 & $(0.97-1.03)$ & 0.984 & 0.99 & $(0.95-1.02)$ & 0.389 & 0.98 & $(0.95-1.02)$ & 0.329 \\
\hline & 2008 & 0.94 & $(0.90-0.99)$ & 0.011 & 0.93 & $(0.89-0.97)$ & 0.002 & 0.92 & $(0.88-0.97)$ & 0.001 \\
\hline & 2009 & 1.01 & $(0.95-1.06)$ & 0.860 & 1.00 & $(0.95-1.06)$ & 0.892 & 1.00 & $(0.95-1.06)$ & 0.958 \\
\hline & 2010 & 0.88 & $(0.82-0.95)$ & 0.001 & 0.88 & $(0.82-0.94)$ & 0.001 & 0.89 & $(0.82-0.95)$ & 0.001 \\
\hline & 2011 & 0.84 & $(0.77-0.92)$ & 0.000 & 0.82 & $(0.75-0.90)$ & $<.0001$ & 0.83 & $(0.75-0.91)$ & $<.0001$ \\
\hline & 2012 & 0.95 & $(0.86-1.06)$ & 0.374 & 0.96 & $(0.87-1.07)$ & 0.471 & 0.96 & $(0.86-1.06)$ & 0.405 \\
\hline
\end{tabular}

Results for Q2-Q4 not shown. Ratios of odds ratios are also presented, with Q5 and traditional fee-for-service serving as referent groups

Therefore, some immigrants would have been mistakenly included with long-term residents. Third, all patients prior to transition were attributed using virtual enrolment, whereas after transition, patients were attributed to physicians using a combination of both virtual and formal enrolment. Fourth, due to the complexity of the analytical models and the sheer size of the analytical dataset, it was not possible to account for heterogeneity among practices in their trends over time by including time as a random effect. Finally, our results cannot be considered generalizable to physicians or patients who transitioned from traditional FFS to other model types.

Future research should explore how more recent large-scale transitions (e.g. from enhanced FFS to primarily capitation-based models) have affected cancer screening and other measures of quality of care for marginalized groups. Importantly, some forms of capitation-based models emphasize team-based care, with non-physician health professionals such as nurse practitioners being integral parts of the primary care team, and it is feasible that the transition to these types of models may be associated with a decrease in screening gaps, as has been suggested for diabetes monitoring [30].

\section{Conclusion}

In this study, we have found that the transition to enhanced FFS was not associated with a reduction in inequities. In fact, inequities generally tended to increase. We also found that early adopters of this new model had higher overall screening, but larger screening gaps for their foreign-born and low-income patients, than later adopters. It remains to be seen how other primary care 
transitions in Ontario have affected cancer screening gaps and other health inequities for immigrant and low-income patients.

\section{Abbreviations}

CAPE: Client agency program enrolment; CRC: Colorectal cancer; FFS: Fee-forservice; ICES: Institute for clinical evaluative sciences; IRCC: Immigration, refugees and citizenship canada; OHIP: Ontario health insurance plan; PEM: Patient enrolment model; RDPB: Registered persons database

\section{Acknowledgements}

This study was supported by a Health System Research Fund grant from the Ontario Ministry of Health and Long-Term Care. No endorsement by the Ministry is intended or should be inferred. Parts of this material are based on data and information provided by Cancer Care Ontario [27]. The opinions, results, view, and conclusions reported in this paper are those of the authors and do not necessarily reflect those of CCO. No endorsement by CCO is intended or should be inferred. Immigration data was obtained from the Immigration, Refugees and Citizenship Canada database held at the Institute for Clinical Evaluative Sciences.

This study was also supported by the Institute for Clinical Evaluative Sciences (ICES), which is funded by an annual grant from the Ontario Ministry of Health and Long-Term Care (MOHLTC). The opinions, results and conclusions reported in this paper are those of the authors and are independent from the funding sources. No endorsement by ICES or the Ontario MOHLTC is intended or should be inferred. Parts of this material are based on data and information compiled and provided by $\mathrm{ClHI}$. However, the analyses, conclusions, opinions and statements expressed in the material are those of the authors, and not necessarily those of $\mathrm{ClHI}$. AL is supported by a Career Development Award in Cancer Prevention from the Canadian Cancer Society Research Institute and a Canadian Institutes of Health Research New Investigator Award. AL and RG are supported as Clinician Scientists through the University of Toronto and St. Michael's Hospital Departments of Family and Community Medicine. MG is supported by the CTAQ Chair in Applied Health Economics/Health Policy.

\section{Funding}

This study was supported by a Health System Research Fund grant from the Ontario Ministry of Health and Long-Term Care. The funder had no role in study design, data collection, analysis or interpretation, or in writing the manuscript.

\section{Availability of data and materials}

The datasets generated and/or analysed during the current study are not publicly available. These datasets are housed at the Institute for Clinical Evaluative Sciences and public access is restricted due to the Personal Health Information Act. De-identified tables are available from the corresponding author on reasonable request.

\section{Authors' contributions}

The authors have each contributed to the preparation of this manuscript. AL contributed to the conception of the study, data interpretation, and to drafting and revising the manuscript. She gave final approval of the version to be published. AM provided advice and direction for the study design and contributed to data analysis and interpretation. She revised the article critically for important intellectual content and gave final approval of the version to be published. MT provided advice and direction for the study design and contributed to data analysis and interpretation. She revised the article critically for important intellectual content and gave final approval of the version to be published. MG provided advice and direction for the study design and contributed to data interpretation. He revised the article critically for important intellectual content and gave final approval of the version to be published. RG provided advice and direction for the study design and contributed to data interpretation. He revised the article critically for important intellectual content and gave final approval of the version to be published. SD contributed to the conception of the study, and provided advice and direction for the study design, and data acquisition, analysis and interpretation. She revised the article critically for important intellectual content and gave final approval of the version to be published. All authors have read and approved the manuscript, and have no competing interests to declare.

\section{Ethics approval and consent to participate}

The research protocol was approved by the institutional review board at Sunnybrook Health Sciences Centre. Participant consent was not necessary as this study involved the use of data from the Institute for Clinical Evaluative Sciences (ICES). ICES is a prescribed entity for the purposes of section 45 Ontario's Personal Health Information Privacy Act. This means that health information custodians like physicians, hospitals or long-term care homes are permitted to disclose personal health information to ICES without consent. This information is for statistical analysis in order to evaluate and monitor aspects of the health system. ICES may also use personal health information under the authority of PHIPA s. 44 for approved research projects. Data custodians outside the health sector may disclose personal information to ICES for specified use under the authority of FIPPA or other datagoverning statutes.

\section{Consent for publication}

Not applicable.

\section{Competing interests}

The authors declare that they have no competing interests.

\section{Publisher's Note}

Springer Nature remains neutral with regard to jurisdictional claims in published maps and institutional affiliations.

\section{Author details}

${ }^{1}$ Department of Family \& Community Medicine, St. Michael's Hospital, 30 Bond St, Toronto, ON M5B1W8, Canada. ${ }^{2}$ Department of Family \& Community Medicine, University of Toronto, 500 University Ave. 5th Floor, Toronto, ON M5G1V7, Canada. ${ }^{3}$ Centre for Urban Health Solutions, Li Ka Shing Knowledge Institute, St. Michael's Hospital, 30 Bond St, Toronto, ON M5B1W8, Canada. ${ }^{4}$ Dalla Lana School of Public Health, University of Toronto, 155 College St. 6th Floor, Toronto, ON M5T3M7, Canada. Institute for Clinical Evaluative Sciences, G1 06, 2075 Bayview Ave, Toronto, ON M4N3M5, Canada. ${ }^{6}$ Ottawa Hospital Research Institute, 501 Smyth Box 511, Ottawa, ON K1H 8L6, Canada. ${ }^{7}$ Department of Family Medicine, Queen's University, 220 Bagot St, Kingston, ON K7L5E9, Canada. ${ }^{8} \mathrm{CT}$ Lamont Primary Health Care Research Centre, Bruyere Research Institute, 43 Bruyère St, Ottawa, ON K1N5C8, Canada. ${ }^{9}$ Department of Family Medicine, University of Ottawa, 600 Peter Morand Crescent Suite 201, Ottawa, ON K1G 5Z3, Canada.

Received: 26 September 2017 Accepted: 14 August 2018

Published online: 29 August 2018

\section{References}

1. Duarte-Franco E, Franco EL. Cancer of the uterine cervix. BMC Womens Health. 2004;4(Suppl 1):S13.

2. Franco EL, Duarte-Franco E, Ferenczy A. Cervical cancer: epidemiology, prevention and the role of human papillomavirus infection. CMAJ. 2001; 164(7):1017-25.

3. Canadian Cancer Society/National Cancer Institute of Canada. Toronto: Canadian Cancer Statistics 2006; 2006.

4. Canadian Task Force on Preventive Health C, Tonelli M, Connor Gorber S, Joffres M, Dickinson J, Singh $\mathrm{H}$, et al. Recommendations on screening for breast cancer in average-risk women aged 40-74 years. CMAJ. 2011;183(17): 1991-2001.

5. Wilkins K, Shields M. Colorectal cancer testing in Canada--2008. Health Rep. 2009;20(3):21-30.

6. Cancer Care Ontario. Ontario Breast Screening Program 20th Anniversary report. Toronto: Cancer Care Ontario; 2010.

7. Cervical Screening - CCO: Cancer Care Ontario; 2012 [Available from: http:// www.cancercare.on.ca/pcs/screening/cervscreening/.

8. Ontario Cancer Plan 2008-2011: Cancer Care Ontario; [updated June 29 2009July 16, 2009]. Available from: http://ocp.cancercare.on.ca/cms/One. aspx?portalid=14464\%pageid $=14471$.

9. CancerCareOntario. Screening - CCO [Available from: http://www.cancercare. on.ca/pcs/screening/. Accessed 20 Aug 2018.

10. Borkhoff CM, Saskin R, Rabeneck L, Baxter NN, Liu Y, Tinmouth J, et al. Disparities in receipt of screening tests for cancer, diabetes and high cholesterol in Ontario, Canada: a population-based study using area-based methods. Can J Public Health. 2013;104(4):e284-90. 
11. Blackwell DL, Martinez ME, Gentleman JF. Women's compliance with public health guidelines for mammograms and pap tests in Canada and the United States: an analysis of data from the Joint Canada/United States Survey Of Health. Womens Health Issues. 2008;18(2):85-99.

12. Lofters A, Guilcher S, Glazier RH, Jaglal S, Voth J, Bayoumi AM. Screening for cervical cancer in women with disability and multimorbidity: a retrospective cohort study in Ontario, Canada. CMAJ Open. 2014;2(4):E240-7.

13. Culleton S, Slater M, Lofters A. Predictors of low colorectal cancer screening in an urban academic family practice. Open J Preventive Med. 2014;4:438-45.

14. Lofters A, Glazier RH, Agha MM, Creatore MI, Moineddin R. Inadequacy of cervical cancer screening among urban recent immigrants: a populationbased study of physician and laboratory claims in Toronto, Canada. Prev Med. 2007:44(6):536-42.

15. Lofters AK, Moineddin R, Hwang SW, Glazier RH. Predictors of low cervical cancer screening among immigrant women in Ontario, Canada. BMC Womens Health. 2011;11:20.

16. Lofters AK, Ng R, Lobb R. Primary care physician characteristics associated with cancer screening: a retrospective cohort study in Ontario, Canada. Cancer Med. 2015;4(2):212-23. https://doi.org/10.1002/cam4.358. Epub 2014 Nov 27.

17. Ramji F, Cotterchio M, Manno M, Rabeneck L, Gallinger S. Association between subject factors and colorectal cancer screening participation in Ontario, Canada. Cancer Detect Prev. 2005;29(3):221-6.

18. Guilcher SJ, Lofters A, Glazier RH, Jaglal SB, Voth J, Bayoumi AM. Level of disability, multi-morbidity and breast cancer screening: does severity matter? Prev Med. 2014;67:193-8.

19. Singh SM, Paszat LF, Li C, He J, Vinden C, Rabeneck L. Association of socioeconomic status and receipt of colorectal cancer investigations: a population-based retrospective cohort study. CMAJ. 2004;171(5):461-5.

20. Glazier RH, Creatore MI, Gozdyra P, Matheson Fl, Steele LS, Boyle E, et al. Geographic methods for understanding and responding to disparities in mammography use in Toronto, Canada. J Gen Intern Med. 2004;19(9):952-61.

21. Lofters AK, Hwang SW, Moineddin R, Glazier RH. Cervical cancer screening among urban immigrants by region of origin: a population-based cohort study. Prev Med. 2010:51(6):509-16.

22. Lofters AK, Moineddin R, Hwang SW, Glazier RH. Low rates of cervical cancer screening among urban immigrants: a population-based study in Ontario, Canada. Med Care. 2010;48(7):611-8.

23. Akers AY, Newmann SJ, Smith JS. Factors underlying disparities in cervical cancer incidence, screening, and treatment in the United States. Curr Probl Cancer. 2007;31(3):157-81.

24. Garner El. Cervical cancer: disparities in screening, treatment, and survival. Cancer Epidemiol, Biomark Prev. 2003;12(3):242s-7s.

25. Coughlin SS, King J, Richards TB, Ekwueme DU. Cervical cancer screening among women in metropolitan areas of the United States by individuallevel and area-based measures of socioeconomic status, 2000 to 2002. Cancer Epidemiol Biomark Prev. 2006;15(11):2154-9.

26. Lobb R, Pinto AD, Lofters A. Using concept mapping in the knowledge-toaction process to compare stakeholder opinions on barriers to use of cancer screening among south Asians. Implementation Sci. 2013:8:37.

27. McColl MA. Disability studies at the population level: issues of health service utilization. Am J Occup Ther. 2005:59(5):516-26.

28. Bigby J, Holmes MD. Disparities across the breast cancer continuum. Cancer Causes Control. 2005;16(1):35-44.

29. Glazier RH, Redelmeier DA. Building the patient-centered medical home in Ontario. JAMA. 2010;303(21):2186-7.

30. Kiran T, Victor JC, Kopp A, Shah BR, Glazier RH. The relationship between primary care models and processes of diabetes care in Ontario. Can J Diabetes. 2014;38(3):172-8.

31. Hutchison B, Glazier R. Ontario's primary care reforms have transformed the local care landscape, but a plan is needed for ongoing improvement. Health Aff (Millwood). 2013;32(4):695-703

32. Kiran T, Wilton AS, Moineddin R, Paszat L, Glazier RH. Effect of payment incentives on cancer screening in Ontario primary care. Ann Fam Med. 2014;12(4):317-23

33. Kralj B, Kantarevi J. Primary care in Ontario: reforms, investments and achievements. Ontario Medical Review. 2012:18-24.

34. OntarioMinistryofFinance. Ontario Fact Sheet April 2016 [Available from: http://www.fin.gov.on.ca/en/economy/ecupdates/factsheet.html. Accessed 20 Aug 2018.
35. Rabeneck L, Tinmouth JM, Paszat LF, Baxter NN, Marrett LD, Ruco A, et al. Ontario's ColonCancerCheck: results from canada's first province-wide colorectal cancer screening program. Cancer Epidemiol Biomark Prev. 2014; 23(3):508-15.

36. Bogler T, Farber A, Stall N, Wijayasinghe S, Slater M, Guiang C, et al. Missed connections: unintended consequences of updated cervical cancer screening guidelines on screening rates for sexually transmitted infections. Can Fam Physician. 2015;61(10):e459-66.

37. Dahrouge S, Glazier, R, Hogg, W. Defining measures of panel size Ottawa: CT Lamont Primary Health Care Research Centre; 2010 [Available from: https://www.uwo.ca/fammed/csfm/siiren/documentation/Dahrouge_Final_ Report_PHCS_Program_Seed_Funding.pdf.

38. Kiran T, Victor JC, Kopp A, Shah BR, Glazier RH. The relationship between financial incentives and quality of diabetes care in Ontario, Canada. Diabetes Care. 2012:35(5):1038-46.

39. Steele LS, Durbin A, Sibley LM, Glazier R. Inclusion of persons with mental illness in patient-centred medical homes: cross-sectional findings from Ontario, Canada. Open medicine. 2013;7(1):e9-20.

40. Primary Care Practice Report. Technical appendix. Toronto: Health Quality Ontario; 2015

41. Kralj B. Measuring "rurality" for purposes of health care planning: an empirical measure for Ontario. Ont Med Rev. 2000:67:33-52.

42. Reid RJ, MacWilliam L, Verhulst L, Roos N, Atkinson M. Performance of the ACG case-mix system in two Canadian provinces. Med Care. 2001; 39(1):86-99.

43. Honein-AbouHaidar GN, Rabeneck L, Paszat LF, Sutradhar R, Tinmouth J Baxter NN. Evaluating the impact of public health initiatives on trends in fecal occult blood test participation in Ontario. BMC Cancer. 2014;14:537.

44. Rudoler D, Deber R, Barnsley J, Glazier RH, Dass AR, Laporte A. Paying for primary care: the factors associated with physician self-selection into payment models. Health Econ. 2015;24(9):1229-42.

45. Dahrouge S, Hogg WE, Russell G, Tuna M, Geneau R, Muldoon LK, et al. Impact of remuneration and organizational factors on completing preventive manoeuvres in primary care practices. CMAJ. 2012;184(2): E135-43.

46. Kiran T, Kopp A, Moineddin R, Glazier RH. Longitudinal evaluation of physician payment reform and team-based care for chronic disease management and prevention. CMAJ. 2015;

47. Vahabi M, Lofters A, Kumar M, Glazier RH. Breast cancer screening disparities among urban immigrants: a population-based study in Ontario, Canada. BMC Public Health. 2015;15:679.

48. kiran T, Kopp A, Glazier RH. Those left behind from voluntary medical home reforms in Ontario, Canada. Ann Fam Med. 2016;14(6):517-25.

Ready to submit your research? Choose BMC and benefit from:

- fast, convenient online submission

- thorough peer review by experienced researchers in your field

- rapid publication on acceptance

- support for research data, including large and complex data types

- gold Open Access which fosters wider collaboration and increased citations

- maximum visibility for your research: over $100 \mathrm{M}$ website views per year

At $\mathrm{BMC}$, research is always in progress.

Learn more biomedcentral.com/submission 